\title{
A CONTEMPORANEIDADE DO PENSAMENTO DE PAULO FREIRE NO CONTEXTO DE DISCUSSAO DA ESCOLA SEM PARTIDO
}

\author{
Andrea Serpa Albuquerque \\ Dileno Dustan Lucas de Souza \\ Simone da Silva Ribeiro ${ }^{(*)}$
}

\section{INTRODUÇÃO}

Nossa intenção neste ensaio é a de, no diálogo com Paulo Freire, refletir e trazer à tona a discussão sobre como, longe da possibilidade de ser um campo neutro, a Educação é - sempre foi e sempre será - um campo de batalhas e disputas ideológicas, afinal, diferentes grupos sociais possuem projetos diferentes para a formação das novas gerações, projetos que revelam valores, princípios, conceitos - e como veremos, preconceitos - diversos. A sociedade, apesar de ser hegemônica, por ação das forças opressoras, jamais será homogênea, sempre será o campo de disputas entre os muitos projetos para o mundo e para os seres humanos que nele vivem. Ignorar isso é ignorar a própria natureza da sociedade humana.

Num momento crucial para a fragilizada democracia brasileira, nossa intenção é a de defender e fortalecer uma escola que seja plural e capaz de refletir sobre todas as temáticas que afloram em nossa sociedade, compreendendo que são questões importantes para todos os sujeitos chamados a se posicionarem diante delas, consistindo em um papel fundamental da escola nutrir esses cidadãos com informações consistentes, plurais e relevantes. Com isso, estamos reafirmando a impossibilidade de neutralidade da educação frente a qualquer assunto, o que não significa adesão a um programa ou projeto de grupos ou partidos; ao contrário, significa a formação de um

\footnotetext{
${ }^{(*)}$ Andrea Serpa Albuquerque. Possui graduação em Pedagogia pela Universidade Federal do Rio de Janeiro (1992), mestrado (2006) e doutorado em Educação pela Universidade Federal Fluminense (UFF)(2010). Atualmente, é professora adjunta da Faculdade de Educação da UFF/Niteroi. E-mail: andreaserpauff@gmail.com.

Dileno Dustan Lucas de Souza. Graduado em Pedagogia pela Universidade Federal do Rio de Janeiro (UFRJ)(1994), mestre em Educação pela Universidade do Estado do Rio de Janeiro (UERJ)(1997), doutor em Educação pela Universidade Federal do Rio Grande do Sul (Ufrgs)(2005) e pós-doutorado pela Universidade Federal de Minas Gerais (UFMG). Atualmente é professor associado da Universidade Federal de Juiz de Fora (UFJF). E-mail: dilenodustand $@$ @mail.com.

Simone da Silva Ribeiro. Docente de educação básica no Colégio de Aplicação João XXIII da Universidade Federal de Juiz de Fora. Possui graduação em Pedagogia pela Universidade do Estado do Rio de Janeiro (1991), mestrado em Educação pela Universidade do Estado do Rio de Janeiro (1998) e doutorado em Educação pelo Programa de PósGraduação em Educação da Universidade Federal de Juiz de Fora (2012). E-mail: simonerib@gmail.com
} 
pensamento crítico e autônomo diante da diversidade do mundo, e não sua indiferença e/ou ignorância sobre questões que pulsam na vida social.

Neste sentido, vamos explorar, a título de exemplo e para ilustrar nosso embate, as propostas do movimento "Escola sem partido" (ESP) e as ideias que representa. Esse movimento vem buscando, por meios jurídicos e midiáticos, fazer com que suas propostas sejam incorporadas e efetivadas, mesmo que tais propostas firam a legislação em vigor e até tratados internacionais. Mas qual é o teor dessas propostas, por que são tão nocivas, causando tanta reação por parte de educadores e intelectuais que refletem a educação brasileira?

Esta e outras questões abordaremos ao longo do texto, buscando trazer o assunto à tona de modo que a discussão se amplie, e possamos sim, refletir e, quem sabe, tomar partido por uma educação que se pense inteira. Afinal, tomar partido, neste sentido, é necessário na educação, pois precisamos nos posicionar, dizer que educação queremos, que educação pensamos, para quem queremos a educação.

\section{EDUCAÇÃO - UM CAMPO DE MUITAS DISPUTAS}

Recentemente, nós educadores e pesquisadores de longa data em Educação, temos sido pegos de surpresa com a rapidez e a inconsistência de várias discussões e até mudanças legais que vêm ocorrendo em nosso sistema educacional, muitas vezes oriundas de sujeitos e organizações historicamente distantes e alheios as discussões e produções científicas da área das últimas décadas, quiçá séculos.

O teor dessas discussões defende, entre outras coisas, desde a possibilidade de censurar os temas contemporâneos e complexos que nos desafiam na buscar de novas e pacíficas formas de convivência entre as diferenças, respeitando a diversidade do mundo, até o "direito" a uma educação "pública" pautada em uma agenda racista, machista, sexista, que defende abertamente a exclusão de muitos em favor de uns poucos, e que ainda ignore, e portanto, aprofunde, ainda mais, as injustiças sociais, questionando direitos básicos dos cidadãos. Além disso, muitos outros temas serão excluídos das discussões de sala de aula, como também, a exclusão completa de disciplinas como história, filosofia e sociologia - e, portanto, um conjunto fundamental de informações e conhecimentos. Para efetivar essas propostas defendem, inclusive, a "criminalização docente" para ameaçar professores e professoras que, cientes de seu papel como formadores, não aceitem ou questionem as "mordaças" e o silenciamento das vozes dissonantes na escola. 
Em outras palavras, um projeto que pretende revogar os princípios de gestão democrática, autonomia e pluralidade no pensamento pedagógico consagrados na LDB (Lei 9.394/96), lei que já começou a sofrer uma série de reformulações absurdas, e que vem se tornando cada dia mais deformada, mas que em seu artigo $3^{\circ}$ afirma:

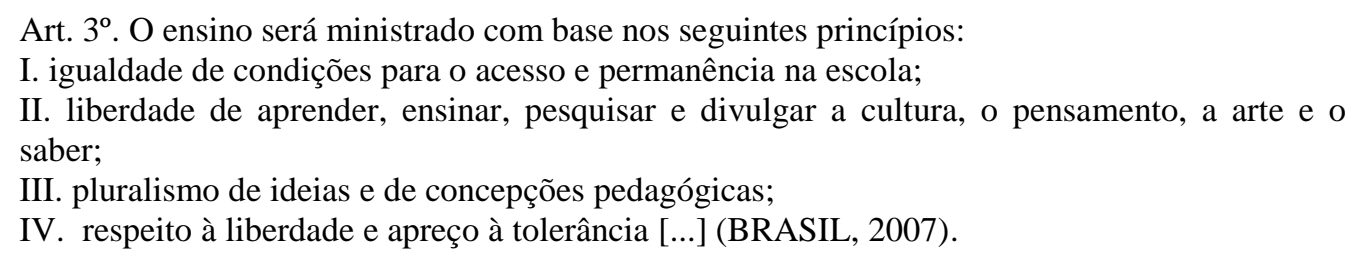

Ao nos referirmos ao movimento "Escola sem partido", nos posicionamos claramente contra um projeto que, em menos de dez anos desde a sua criação, vem propagando ideias e atuando no sentido da aprovação de leis que, ferindo até a constituição brasileira, buscam limitar e censurar programas de ensino, as aulas e até mesmo o professor no exercício da função para o qual foi formado, em todas as escolas brasileiras.

No sítio do movimento ${ }^{1}$ uma das páginas tem o título "Por uma lei contra o abuso da liberdade de ensinar". Entre outras proposições, o projeto, apresentado na forma de projeto de lei, propõe que seja proibido, nas aulas de qualquer disciplina ou nível de ensino, o que o movimento nomeia de prática de doutrinação política e ideológica e o ensino de conteúdos e a realização de atividades que possam entrar em conflito com convicções religiosas ou morais das famílias. É interessante iniciarmos por esta questão, porque desde sempre, mas mais intensamente durante as décadas de oitenta e noventa do século passado, educadores de todo o Brasil vem lutando por políticas públicas que garantam o acesso de todos os brasileiros a uma educação democrática, autônoma e plural. E junto com esses educadores nos surpreendemos e nos preocupamos seriamente, com um movimento que preconiza - em uma sociedade democrática - que a "liberdade" é um "abuso".

Defendemos - abusadamente - que uma educação de qualidade e significativa produza conhecimentos a partir do pensamento crítico, do debate e reflexão. No entanto, para quem acusa estas práticas de "doutrinação" sugere que sejam substituídas pelas práticas pedagógicas "neutras”.

Todo educador bem formado e informado sabe que não existem, ou é possível existirem, práticas pedagógicas neutras. Como não existem ciência neutra, ou tecnologia neutra, arte neutra ou qualquer produção humana neutra. Assim como é impossível a qualquer ser humano inserido em uma sociedade não exercer seu papel político. Somos convocados a refletir, ponderar e nos

\footnotetext{
${ }^{1}$ Dis.: http://www.programaescolasempartido.org.
} 
posicionar contra ou a favor sobre todos os aspectos da vida social, cultural, econômica e, portanto, a assumir uma posição, tomar partido, o que não implica ter um partido ou ser militante partidário, mesmo que isso também seja saudável, legítimo e um direito dos cidadãos. Afinal, ainda não inventaram em nosso tempo histórico uma democracia sem partidos políticos, e muitos dos defensores da "escola sem partido" ou dos "professores sem partido" exercem plenamente seu direito civil e a liberdade de defender sua ideologia, exercendo, inclusive, cargos públicos.

No contexto político mais amplo, de onde partem estas e outras proposições igualmente sem respaldo, não houve nenhum debate mais amplo com a sociedade como um todo ou sequer um diálogo mais aprofundado com os renomados pesquisadores e cientistas das ciências humanas, o que de certa forma, não é, infelizmente, estranho ou novidade para nós brasileiros e brasileiras.

País de um passado colonial, depois de décadas de ditadura e total subordinação econômica e cultural aos países ditos desenvolvidos por seu domínio financeiro global, temos consciência do quanto ainda é frágil nossa jovem democracia, e do quanto ainda estão enraizadas em nossas práticas cotidianas atitudes autoritárias, abusivas, desrespeitosas e parciais. E pelo que parece, alguns tem absoluto fascínio por elas. Sentem-se desrespeitados pela "liberdade" do outro. Ressentem-se da liberdade. Ressentem-se do direito do outro a vida. Ressentem-se do direito do outro pensar diferente. Ressentem-se dos "abusados" que insistem em ser "livres".

\section{PAULO FREIRE - EDUCAÇÃO É POLÍTICA}

Ao trazermos Freire para esta discussão, precisamos primeiro colocá-lo em seu devido lugar neste contraponto histórico. Precisamos, antes de qualquer coisa, reconhecer sua inegável genialidade e importância para a Educação ocidental, como o brasileiro mais homenageado da história, com 29 títulos de Doutor Honoris Causa de renomadas universidades na América e Europa, prêmio da Unesco de "Educação para a Paz" em 1986, o único autor brasileiro a constar na bibliografia dos cem livros mais lidos nas universidades de língua inglesa. Feito que ainda não encontrou sucessor no país, e nem em muitos outros. Esse é o lugar de Freire na história internacional da Educação.

Segundo, precisamos dizer de sua capacidade de contribuir com reflexões acerca de questões contemporâneas de modo que suas obras situam-se tanto no campo da resistência política aos discursos fascistas que fundamentam projetos como a Escola sem Partido, como no campo de uma discussão teórica que precisamos urgente retomar com jovens professoras e professores deste 
século. Neste sentido, as lutas travadas por Freire contra uma sociedade elitista, excludente e perversa, ainda se fazem, infelizmente, presentes e cada dia mais necessárias.

Freire foi, e ainda é, pois sua influência supera sua morte, um educador que ousou sonhar um mundo mais humano no qual a educação tem um papel determinante. Militante, no sentido de ser alguém que sonha e luta por ideais, empenhado na construção da educação libertadora, já que entendia que esta seria a única capaz de nos fazer livres, das condições de aprisionamento e de coisificação as quais estamos submetidos, e talvez por isso mesmo odiado por todos os que preferem o aprisionamento e silenciamento do outro. Ao retomarmos sua vasta obra, encontramos um intelectual coerente que nos mostra a importância da necessária militância na educação entendida como um ato político -, contrariando toda a visão que se propunha a uma concepção de educação como uma prática neutra.

Freire já nos dizia, no final do século passado que a educação popular como "um nadar contra a corrente", é a que: [...]"substantivamente democrática, não separa do ensino dos conteúdos o desvelamento da realidade"; [...] "estimula a presença organizada no sentido da superação das injustiças sociais"; [...] "respeita os educandos e por isso mesmo leva em consideração seu saber de experiência feito, a partir do qual trabalha o conhecimento com o rigor de aproximação dos objetos"; [...] "trabalha, incansavelmente, a boa qualidade do ensino"; [...] "capacita suas professoras cientificamente à luz dos recentes achados em torno da aquisição da linguagem, do ensino da escrita e da leitura"; [...] "em lugar de negar a importância da presença dos pais, da comunidade, dos movimentos populares na escola, se aproxima dessas forças com as quais aprende para com elas poder ensinar também"; "supera preconceitos de raça, de classe, de sexo e se radicaliza na defesa da substantividade democrática.” (FREIRE, 1993, p. 49).

Esta educação popular, que incorporamos a nossa reflexão, concebe o conhecimento como possibilidade de superação de relações verticalizadas, onde uns sejam oprimidos e tenham que se submeter, enquanto outros vivem da opressão e da submissão. E esta concepção nunca foi tão atual.

O conhecimento, pelo contrário, exige uma presença curiosa do sujeito em face do mundo. Requer uma ação transformadora sobre a realidade. Demanda uma busca constante. Implica em intervenção e em reinvenção. Reclama a reflexão crítica de cada um sobre o ato mesmo de conhecer, pelo qual se reconhece conhecendo e, ao reconhecer-se assim, percebe o "como" de seu conhecer e os condicionamentos a que está submetido seu ato. (FREIRE, 1983, 27).

Não assumimos uma posição nostálgica, de um tempo que já passou, como se o passado fosse melhor ou pior dependendo do ponto de vista. Estamos sim, afirmando que, o contexto geral e as condições estruturais aos quais estamos submetidos na sociedade não se transformaram, apesar 
de que os avanços sociais na direção dos quais o Brasil engatinhava nas últimas décadas podem ser o estopim que deu origem ao momento atual. Como por exemplo, uma lei de diretrizes e bases que preconiza a gestão democrática das escolas. A Lei 10.639/2003, que preconiza o ensino de cultura e história afro-brasileira e africana na educação básica, a adoção de cotas para acesso à educação técnica e superior em instituições públicas. Vivemos um momento de reação que pode nos levar a um grande retrocesso e perda das poucas conquistas alcançadas, sobretudo em educação. Mas é também Freire que nos aponta a questão que está colocada:

Não há prática educativa, como de resto nenhuma prática, que escape a limites. Limites ideológicos, epistemológicos, políticos, econômicos, culturais. Creio que a melhor afirmação para definir o alcance da prática educativa em face dos limites a que se submete é a seguinte: não podendo tudo, a prática educativa pode alguma coisa. (FREIRE, 1993, p. 47).

Reconhecemos que toda proposta educativa é política, todo educador é um sujeito que atua no campo da política diariamente, porque entendemos que política não está restrita a ação de um partido ou um grupo social, mas é a forma de estar no e com o mundo. Como sujeitos sociais construímos esse nosso estar no e com o mundo na interação com outros, assim a educação pode se omitir e se esconder atrás de uma pseudoneutralidade ou pode entender que há vários projetos em disputa e que nosso papel, enquanto educadores, é o de construir relações solidárias, democráticas e emancipadas.

É nesse sentido também que, tanto no caso do processo educativo quanto no do ato político, uma das questões fundamentais seja a clareza em torno de a favor de quem e do quê, portanto contra quem e contra o quê, fazemos a educação e de a de a favor de quem e do quê, portanto contra quem e contra o quê, desenvolvemos atividade política. Quanto mais ganhamos clareza através da prática, tanto mais percebemos a impossibilidade de separar o inseparável: a educação da política. (FREIRE, 1989, p. 14).

Não é nossa proposta defender que um projeto deva prevalecer sobre os demais, ou defender o silenciamento da pluralidade das cosmovisões que formam o caldo social. Ao contrário, reconhecemos que, assim como na sociedade, são muitos os caminhos possíveis, são muitos os currículos que se escrevem e se inscrevem no corpo dessa escola. E nós, como Freire e tantos outros celebres educadores que dedicaram suas vidas a educação popular no Brasil, defendemos o “diálogo" como princípio pedagógico. O diálogo que permite que uma nação democrática, amadurecida, digna para todos emerja das cinzas de tantos anos de tirania. O diálogo é o caminho que expressa nossas contradições e nos permite crescer, coletivamente, construindo um país que seja bom para todos e não apenas bom para os homens brancos, héteros, ricos e cristãos. Bom apenas para os exploradores como era nos tempos de colônia. No entanto o "diálogo" ou uma educação dialogizada, por si só, já aterroriza aqueles que vem a liberdade do outro como uma 
ameaça àqueles que desejam viver no mundo onde "manda quem pode e obedece quem tem juízo", onde a liberdade apavora e desvela minha "autoridade" e meus privilégios de homem branco.

Defender o diálogo com as diferenças não significa fugir a luta respeitosa, mas necessária e firme contra os nossos contrários. Não podemos ser condescendentes ou coniventes - e nem mesmo tolerantes - com projetos que apenas desejam o silenciamento, a exclusão e, até mesmo como ouvimos publicamente em tantos discursos que circulam em nossa sociedade atual, o aniquilamento moral, social e físico do outro. Ou nas palavras do próprio Freire: “a democracia e a liberdade encontram-se esboçadas nesta etapa de transição como possibilidades históricas. Elas não se efetivam sem luta." (FREIRE, 2006, p. 25).

Enfrentamos projetos que não parecem defender ou mesmo desejar o diálogo. Não respeitam ou defendem a democracia. Desejam apenas a submissão, a opressão e a imposição de suas próprias ideias de forma autoritária a toda a sociedade, a qualquer custo, a qualquer preço. Segundo o pensador italiano Antônio Gramsci, o termo ideologia refere-se à concepção de mundo, ou seja, não há um olhar apenas, mas sim múltiplos olhares que percebem o mundo e suas idiossincrasias. Não existe neutralidade, qualquer proposta que se diz sem ideologia, na verdade, está omitindo ou negando seu teor ideológico; ou seja, não deixa clara qual é a visão de mundo na qual está baseada, ou compreende que apenas a "sua" ideologia é verdadeira, enquanto as demais são "doutrinas", pressuposto típico das religiões de fanáticos religiosos, afeitos a pensar o mundo de forma dogmática e maniqueísta. Freire enfrenta, abertamente, a ideia de neutralidade em educação:

Do ponto de vista, porém, dos interesses dominantes, é fundamental defender uma prática educativa neutra, que se contente com o puro ensino, se é que isto existe, ou com a pura transmissão asséptica de conteúdos, como se fosse possível, por exemplo, falar da "inchação" dos centros urbanos brasileiros sem discutir a reforma agrária e a oposição a ela feita pelas forças retrógradas do país. Como se fosse possível ensinar não importa o quê, lavando as mãos, indiferentemente, diante do quadro de miséria e de aflição a que se acha submetida a maioria de nossa população. (FREIRE, 1993, p. 49).

Para os ideólogos da "neutralidade" a divisão do mundo entre classes, sejam dominados e dominantes, opressores ou oprimidos é uma "invenção" do pensamento progressista - ou de esquerda - e a rejeitam, acusando os teóricos que a defendem de promover a desarmonia na sociedade - ou no corpo social para usarmos a velha expressão de Durkheim - produzindo inveja e rancores desnecessários entre as classes. Desse modo, rejeitando qualquer análise de origem sócio, histórica e cultural, defendem que o mundo das desigualdades e injustiças é "naturalmente" assim. Um efeito das diferenças estabelecidas pela genética, pela vontade, pelo dom, pela seleção natural dos indivíduos mais capazes; em outras palavras pelo mérito de cada um ou pela vontade de Deus. 
Ao negarem as circunstâncias históricas - sociais, culturais, políticas - que formam a sociedade, cobrindo essas circunstâncias com o manto da pseudoneutralidade dos conhecimentos, projetos como Escola sem Partido, além de naturalizar as diferenças produzidas nas práticas políticas, aprofundam ainda mais essas diferenças, e ao fazerem isso, buscam garantir que grande parte da população permaneça alheia ao conhecimento científico, histórico e social, o que limita em grande parte sua possibilidade de compreensão, participação ou intervenção do jogo político e nos rumos do próprio país. Sendo portanto, um ataque direto a formação do cidadão e a construção de uma democracia de fato.

A democracia é, como todo saber, uma conquista de todos. Toda a separação entre os que sabem e os que não sabem, do mesmo modo que a separação entre as elites e o povo, é apenas fruto de circunstâncias históricas que podem e devem ser transformadas. (FREIRE, 2006, p. 20).

\section{PAPEL DA EDUCAÇÃO NA MUDANÇA}

É interessante refletir sobre como a educação, em momentos de crise, é sempre uma das primeiras a ser sucateada e desqualificada. Não há governo ou governante que não tenha o "seu" projeto de educação ou que proponha mudanças e reformas nos projetos em andamento. Atualmente vivemos um momento de intensa reforma na legislação e nos programas e projetos educacionais em curso, mas o que podemos identificar em comum a toda essa "mudança" é a forma como ela está ocorrendo, ou seja, de forma arbitraria e sem participação social em suas muitas representações legítimas e sem a participação do corpo de cientistas, pesquisadores, doutores e das universidades de modo em geral, optando por reunir-se a portas fechadas com leigos e midiáticos representantes de fragmentos coniventes da sociedade. Um Projeto de Educação que exclui os educadores.

De modo geral, outra característica que perpassa as reformas ou intenções de reforma em curso é a necessidade de promover mudanças na estrutura jurídica de proteção ao direito à educação, de forma a limitar a liberdade de ensino, além de vedar o desenvolvimento de políticas públicas educacionais nos campos da diversidade e formação para a cidadania.

A escola é e sempre será palco de múltiplas controvérsias, de conflitos e diferenças. Ela nasce com a marca da contradição, não há como negar o lugar de reprodução e ao mesmo tempo de renovação que a educação assume na formação das novas gerações. Como nos diz Freire: "A cultura é enquanto está sendo. Só permanece porque muda. Ou talvez dizendo melhor: a cultura só “dura” no jogo contraditório da permanência e da mudança.” (FREIRE, 1983, p. 54). Por isso, o problema não é a mudança ou as divergências em torno do que deve ser ensinado ou não nas 
escolas, mas o mascaramento, sob a égide da neutralidade, do discurso único. Pode-se afirmar que, se existe algo de perigoso em educação é a omissão, é o discurso que não se declara, que se mantém latente, podendo aí sim estar em curso - como tantas vezes esteve - uma estratégia de manipulação.

A construção de uma escola do pensamento único, pautada nos pressupostos de uma certa racionalidade técnica e gerencial, interessa a quem? Quem escolhe o conteúdo, o conhecimento, as ideologias que devem ou não entrar nas escolas? Não parece que esta seja uma questão menor ou para a qual não haja resposta. Muito pelo contrário, há sim muitas definições e restrições àquilo que entendemos como conteúdo ou conhecimentos que devem ser explorados nas escolas e, a grosso modo, estes foram "escolhidos" a despeito de outros, ou seja, representam, em última análise uma ou mais ideologias latentes nestas escolhas. Isso não é condenável ou deve ser negado, é uma constatação e não poderia ser diferente, sempre será uma escolha, sempre haverá uma intencionalidade. A boa escola e a boa educação não desconsideram as divergências, as diferenças, a pluralidade de ideias e concepções, inclusive sobre o que é e como é ensinado.

A escola não pode e não deve ser doutrinária, ou seja, ela não pode fazer propaganda política partidária ou criar artifícios para induzir alguém a se filiar a determinada corrente de pensamento, o papel da escola é ensinar a pensar sobre os muitos projetos de mundo, seus prós e contras, sua história, suas diversas faces, suas escolhas e suas consequências para a vida humana neste planeta. É ensinar a pensar.

Mesmo durante os períodos de ditadura, quando a intenção "neutra" da escola limitava-se a treinar, adestrar, copiar, decorar e reproduzir fragmentos de informações desconexas, o êxito da empreitada pode ser questionado, pois não há como limitar, restringir ou impedir a capacidade humana de pensar, refletir e questionar. E como isso assusta ao poder e as elites é preciso garantir o mínimo e não o fundamental em termos de educação.

Essa aliás vem sendo historicamente uma das principais causas do Brasil não crescer e atingir seu potencial como nação. Como dizia Darcy Ribeiro, uma "elite perversa e mesquinha" não permite que o Brasil se torne a grande nação que poderia ser. Sempre encurralados entre oferecer uma educação suficiente para manter a produção e a exploração pelo capital desse imenso mercado e o perigo de que essa educação seja tanta que produza um cidadão capaz de outras leituras, um sujeito capaz de se sublevar sob os desígnios do mercado, libertando-se deste para se tornar produtor de sua própria história. Para os senhores de engenho, herdeiros das capitanias, precisamos de um pouco de educação, mas não muita. É preciso controlar muito bem o que se ensina e o que se 
aprende. Por isso os verdadeiros educadores não são convidados a sentarem-se nessa mesa, para comungar desse projeto contra o povo e contra o país.

Não é possível exigir que os sujeitos sejam isentos de opinião, pode-se, aliás, deve-se buscar fazer do ambiente escolar o mais diverso, com diferentes visões de mundo e correntes de pensamento plurais o quanto possível. Qualquer outra possibilidade ou tentativa de restringir a diferença acaba sendo sempre uma forma de encobertar um pensamento que está subjacente e enraizado, uma forma de querer reproduzir sempre mais do mesmo, ou seja, perpetuar o mundo tal como ele é, o que no nosso caso isso significa aprofundar a injustiça e a exclusão de muitos para garantir o privilégio de poucos.

A mudança que a escola deve buscar não é a de silenciamento, mas sim de ampliação do diálogo. Ou, como nos diz Freire, o que se pretende com o diálogo é a problematização dos próprios conhecimentos em sua indiscutível relação com a realidade concreta na qual se gera e sobre a qual incide, para melhor compreendê-la, explicá-la, transformá-la. E a transformação assusta muitíssimo aqueles que se alimentam da miséria e só progridem exatamente na manutenção do ignorancia desse um povo.

\section{CONSIDERAÇÕES FINAIS}

Vivemos um processo de disputa, de um lado estão aqueles que buscam combater a pluralidade, defendendo o pensamento único, a homogeneização das práticas, silenciando as diferentes vozes dos sujeitos. Dessa forma almejam ocultar os seus próprios interesses, pois, ao levantarem a bandeira do pensamento único, como se este fosse universal, omitem o fato de que estão, na verdade, promovendo o pensamento do seu próprio grupo e defendendo seus interesses de casta.

Por outro lado, nenhuma tentativa de calar ou silenciar totalmente os sujeitos será bem sucedida, pois sempre haverá aqueles que, contra as tentativas de controle, reinventam suas maneiras de estar no mundo, reafirmando-o com lugar da pluralidade, da partilha, da construção coletiva, de conhecimentos e identidades.

Construir conhecimentos de forma neutra não é possível e nunca o foi, em nenhum lugar ou época da história humana. Ao contrário, o processo de construção de conhecimentos é eminentemente plural, por isso a escola precisa ser o lócus de várias ideias diferentes que possam ser apresentadas e discutidas para que essas ideias possam ser o alimento de novas ideias. E o mundo precisa urgente de novas ideias. 
Novas ideias para o convívio e respeito social entre essas tantas culturas que hoje vivem o maior movimento migratório dos últimos séculos e imprimem uma nova configuração no cenário mundial. Novas ideias sobre cultura, sobre identidade, sobre hibridismo, sobre o eu, o outro e nosso direito humano a existência. Novas ideias sobre outras formas de ser e estar no mundo, e sobre outras formas de organização social, econômica e política que superem os modelos anacrônicos do século XX que vem exaurindo o planeta e ameaçando a existência de todos nós.

O novo é nossa única possibilidade de vida. Não podemos permitir esse retorno a um passado bárbaro, obscuro, autoritário e preconceituoso, simplesmente porque os recursos do planeta não o suportaria por mais um século, e os do nosso país, que pareciam abundantes somem na fumaça todos os dias. Não podemos permitir que projetos fascistas de uma elite "perversa e mesquinha" floresça, simplesmente porque a miséria humana produzida por esse projeto seria tanto que nos arrastaria para uma nova idade das trevas, com mais conflitos, mais violência, bestialidade. Pois a história ensina que onde há intolerância e opressão, principalmente como face assumida do Estado, a violência reina.

Um projeto que nasce claramente no medo das forças conservadoras diante de uma juventude "abusadamente livre" que surpreendeu o país inteiro ao ocupar suas escolas, defendendo a Educação, não se intimidando diante da "autoridade" dos senhores engravatados, e mostrando aos adultos que cabeças que pensam não são fáceis de convencer ou dobrar diante de ameaças autoritárias e discursos demagógicos.

Sempre que a juventude, que a cultura, que a arte começam a questionar o status quo da sociedade, apontando-lhe suas contradições, seus antagonismos e tensões o tecido social esgarça-se as entranhas aparecem e as forças reacionárias realinham-se.

Quando autoridade dos "senhores respeitáveis" torna-se insuficiente para silenciar as perguntas de verdades inconvenientes, quando sua posição - hétero, rica, cristã e branca - torna-se insuficiente para sustentar suas mentiras "tão eloquentes", só a violência e o silenciamento restam como argumentos. É preciso calar essa juventude. É preciso calar seus professores. É preciso calar os artistas. É preciso calar esse povo com uma educação bancária, rasa, inútil. E para calar esse povo o melhor é criar um simulacro de escola: sucateada, terceirizada, vazia de conteúdo significativo, vigiada e privada de reflexão, usurpada de todo e qualquer sentido. É preciso calar esse povo para governar sobre ele. E a escola, produz vozes demais. Faz barulho demais. 
E, sem nenhuma intenção de encerar esta conversa, desejamos ter revivido as possibilidades de manter a esperança, afinal nosso papel enquanto educadores ainda é o de sonhar e construir o sonho com os sujeitos com os quais interagimos. 


\section{REFERÊNCIAS}

FREIRE, Paulo. Extensão ou comunicação. Rio de Janeiro. Paz e Terra, 1983.

Educação como prática da Liberdade. Rio de Janeiro. Paz e Terra. 2006.

Política e Educação: ensaios. 5. ed. São Paulo: Editora Cortez, 1993. Col. Questões de nossa época.

. A importância do ato de ler: em três artigos que se completam. São Paulo. Autores Associados/Cortez, 1989. (Col. Polêmicas do nosso tempo; 4.

BRASIL. Lei 9.394, de 20 de dezembro de 1996. Estabelece as diretrizes e bases da educação nacional. Diário Oficial da União. Brasília: Poder Legislativo, 23 dez. 1996, sec. I, n. 248, p. 27.833. Disp.: <http://www.planalto.gov.br/ccivil 03/leis/L9394.htm>. Acesso: 20 de abril de 2017.

\section{RESUMO}

Recentemente, nós educadores e pesquisadores de longa data em Educação, temos sido pegos de surpresa com a rapidez e a inconsistência de várias discussões e até mudanças legais que vêm ocorrendo em nosso sistema educacional, muitas vezes oriundas de sujeitos e organizações historicamente distantes e alheios as discussões e produções científicas da área das últimas décadas, quiçá séculos. Neste ensaio buscamos refletir sobre o contexto de onde vêm estas discussões e mudanças procurando contrapor as premissas e os argumentos que as sustentam. Para dar conta desta tarefa buscamos um diálogo com Paulo Freire, pois além de reconhecermos sua inegável genialidade e importância para a Educação ocidental, precisamos dizer de sua capacidade de contribuir com reflexões acerca de questões contemporâneas de modo que suas obras se situam tanto no campo da resistência política, como no campo de uma discussão teórica que precisamos urgente retomar com os jovens educadores deste século.

Palavras-chave: Paulo Freire, Escola Sem Partido, Política.

\section{RESUMEN}

Recientemente, los educadores e investigadores de larga data en Educación, hemos sido sorprendidos por la rapidez y la inconsistencia de varias discusiones e incluso cambios legales que vienen ocurriendo en nuestro sistema educativo, muchas veces oriundas de sujetos y organizaciones históricamente distantes y ajenos a las mismas discusiones y producciones científicas del área de las últimas décadas, quizá siglos. En este ensayo buscamos reflexionar sobre el contexto de donde vienen estas discusiones y cambios buscando contraponer las premisas y los argumentos que las sostienen. Para dar cuenta de esta tarea buscamos un diálogo con Paulo Freire, pues además de reconocer su innegable genialidad e importancia para la Educación occidental, necesitamos decir de su capacidad de contribuir con reflexiones acerca de cuestiones contemporáneas de modo que sus obras se sitúan tanto en el campo de la educación resistencia política, como en el campo de una discusión teórica que necesitamos urgentemente retomar con los jóvenes educadores de este siglo.

Palabras-clave: Paulo Freire, Escuela Sin Partido, Política.

\section{ABSTRACT}

Recently, we educators and long-standing researchers in Education have been taken by surprise with the speed and inconsistency of various discussions and even legal changes that have been taking place in our educational system, often coming from historically distant subjects and organizations and discussions and scientific productions of the area of the last decades, maybe centuries. In this essay we seek to reflect on the context of where these discussions and changes come from, trying to counter the premises and the arguments that sustain them. In order to deal with this task, we seek a dialogue with Paulo Freire, because in addition to recognizing his undeniable genius and importance for occidental Education, we need to speak of his capacity to contribute with reflections on contemporary issues so that his works are situated both in the field of political resistance, as in the field of a theoretical discussion that we need urgently to resume with the young educators of this century.

Keywords: Paulo Freire, School without Party, Politics. 